\section{(2) OPEN ACCESS}

\title{
Increased risk of suicide after occupational injury in Korea
}

\author{
Hye-Eun Lee $\left(10,{ }^{1,2}\right.$ Inah Kim ${ }^{0},{ }^{3}$ Myoung-Hee Kim, ${ }_{1}^{4}$ Ichiro Kawachi $^{2}$
}

${ }^{1}$ Korea Institute of Labor Safety and Health, Seoul, The Republic of Korea

${ }^{2}$ Department of Social and Behavioral Sciences, Harvard T.H Chan School of Public Health, Boston, Massachusetts, USA

${ }^{3}$ Occupational and Environmental Medicine, Hanyang University College of Medicine, Seongdong-gu, The Republic of Korea

${ }^{4}$ People's Health Institute, Seoul, The Republic of Korea

Correspondence to Professor Inah Kim,

Occupational and Environmental Medicine, Hanyang University

College of Medicine,

Seongdong-gu 04763, The

Republic of Korea;

inahkim@hanyang.ac.kr

Received 10 May 2020

Revised 29 June 2020

Accepted 10 July 2020

Published Online First

13 August 2020

\section{Check for updates}

(c) Author(s) (or their employer(s)) 2021. Re-use permitted under CC BY-NC. No commercial re-use. See rights and permissions. Published by BMJ.

To cite: Lee $\mathrm{H}$-E,

Kim I, Kim M-H, et al.

Occup Environ Med

2021:78:43-45.

\section{ABSTRACT}

Objectives This study sought to investigate the association between occupational injury and subsequent risk of suicide in Korea.

Methods We linked compensation data for 775537 workers injured at work during 2003-2014 with National Death Registry through 2015. Suicide among injured workers was compared with the economically active population in Korea separately for men and women by calculating SMRs, with $95 \% \mathrm{Cls}$.

Results Injured workers showed higher mortality from suicide for both men (SMR=2.22, 95\% Cl 2.14 to 2.31) and women (SMR=2.11,95\% Cl 1.81 to 2.45) compared with the economically active population in Korea.

Conclusions Occupational injuries are associated with substantially elevated suicide risk in Korea. The results suggest the importance of social policies to protect and support injured workers as well as intensifying efforts to prevent workplace injuries.

\section{INTRODUCTION}

South Korea's suicide rate (24.6 per 100000 in 2016) is the highest among the Organisation for Economic Cooperation and Development countries. ${ }^{1}$

Occupationally injured workers are a potential high-risk group for suicide. Financial insecurity is one of major driver of suicide. ${ }^{2}$ Around $40 \%$ of occupationally injured workers lost their job during treatment and half of injured workers could not return to work for up to a year after claim closure in Korea. ${ }^{3}$ Moreover, injured workers are at greater risk of becoming depressed compared with non-injured workers. ${ }^{4}$ As depression is the obvious proximal cause of suicide, an occupational injury could be linked to suicide via depression. Finally, occupationally injured workers may suffer lingering disabilities, which are also linked with a higher risk of suicide. ${ }^{5}$

Considering that Korea had two times the fatal injury rate compared to the USA in the early $2000 s,{ }^{6}$ the consequence of occupational injury might be greater in Korea than in western countries. However, to our knowledge, there has been no study investigating an association between occupational injury and completed suicide in Korea. Therefore, the purpose of the current study was to examine prospectively the risk of suicide among occupationally injured workers based on large nation-wide longitudinal data.

\section{METHODS}

\section{Study population}

Our data were derived from the Korean workers' compensation database operated by the Korea

\section{Key messages}

What is already known about this subject?

- Occupational injury can be associated with disability and depression, which could be risk factors of suicide.

What are the new findings?

- We found that occupationally injured workers have a significantly higher risk of suicide compared to the economically active population in South Korea. The association was clearer among injured workers without disability.

How might this impact on policy or clinical practice in the foreseeable future?

- Social policies to protect and support injured workers are needed, as well as stronger policies to prevent workplace injuries.

Workers' Compensation and Welfare Service (COMWEL). Injuries that require more than 3 days of medical treatment are accepted for compensation by the Industrial Accident Compensation Insurance (IACI) Act in Korea. We used the data of compensated workers whose accidents occurred between 2003 and 2014. Among a total of 862240 compensated workers, we restricted the sample to workers aged 15-79 years, and claims with International Classification of Diseases (ICD)-10 code S\&T (injury, poisoning and certain other consequences of external causes) or $\mathrm{V}$ to $\mathrm{Y}$ (external causes of morbidity and mortality) excluding the occupational illness such as musculoskeletal disorders. We additionally excluded individuals whose occupational injury was ICD codes W42 (exposure to noise, $\mathrm{n}=22$ ), W43 and T752 (exposure to vibration, $\mathrm{n}=65$ ) which may be classified as chronic condition. Self-harm (X60-X84, $\mathrm{n}=60)$ was excluded to control potential confounders. Those who died from occupational injury $(n=6723)$ were also excluded. Our analytic sample comprised 618718 men and 156819 women.

\section{Ascertainment of outcomes}

The injured workers' data set was merged with the death registry of the Korea for the period 20032015. Death due to intentional self-harm (ICD-10 code X60-X84) were used as our outcome.

\section{Variables}

We used information on employment type, disability and injured sites provided by COMWEL 


\begin{tabular}{|c|c|c|c|c|c|c|}
\hline & \multicolumn{2}{|l|}{ Total } & \multicolumn{2}{|l|}{ Men } & \multicolumn{2}{|c|}{ Women } \\
\hline & SMR & $95 \% \mathrm{Cl}$ & SMR & $95 \% \mathrm{Cl}$ & SMR & $95 \% \mathrm{Cl}$ \\
\hline Total & 2.21 & 2.13 to 2.30 & 2.22 & 2.14 to 2.31 & 2.11 & 1.81 to 2.45 \\
\hline \multicolumn{7}{|c|}{ Employment type } \\
\hline Permanent & 2.25 & 1.96 to 2.57 & 2.21 & 1.91 to 2.55 & 2.68 & 1.66 to 4.09 \\
\hline Temporary & 2.61 & 2.28 to 2.97 & 2.56 & 2.22 to 2.93 & 3.61 & 2.06 to 5.85 \\
\hline \multicolumn{7}{|l|}{ Disability } \\
\hline No & 2.39 & 2.28 to 2.50 & 2.41 & 2.30 to 2.53 & 2.06 & 1.71 to 2.46 \\
\hline Mild & 2.00 & 1.87 to 2.13 & 1.98 & 1.85 to 2.12 & 2.24 & 1.63 to 2.99 \\
\hline Moderate & 1.75 & 1.40 to 2.15 & 1.71 & 1.36 to 2.12 & 3.06 & 0.83 to 7.82 \\
\hline Severe & 1.56 & 0.91 to 2.50 & 1.60 & 0.93 to 2.57 & - & - \\
\hline \multicolumn{7}{|l|}{ Injured site } \\
\hline Head & 2.43 & 2.04 to 2.87 & 2.46 & 2.06 to 2.91 & 1.86 & 0.60 to 4.33 \\
\hline Limbs & 2.21 & 2.11 to 2.32 & 2.22 & 2.12 to 2.33 & 2.07 & 1.68 to 2.52 \\
\hline Others & 2.19 & 2.04 to 2.33 & 2.18 & 2.04 to 2.34 & 2.20 & 1.70 to 2.80 \\
\hline
\end{tabular}

for stratified analysis. Disability caused by the occupational injury was coded into 14 disability ratings according to IACI Act, and further collapsed into four groups: ' $1-3$ ' (severe), '4-7' (moderate), '8-14' (mild) and 'no disability'.

\section{Statistical analysis}

Person-years at risk were calculated starting from the date of the accident until the date of death, the date of reaching age 80 years, or the end of follow-up whichever comes first. Individuals who were not matched with death registry were considered alive and were censored at the end of study. To calculate SMRs, person-years were stratified by sex, 5-year age groups and 1 -year calendar periods. As suicide rates in Korea showed wide gap between men and women, the analysis was performed separately by gender. We calculated the suicide rates of the reference population, the economically active population of South Korea, using data from National Death Registration and the national Economically Active Population Survey (EAPS). Employed or employment seeking persons aged more than 15 are defined as economically active by EAPS. The 95\% CIs for SMR were calculated with the assumption of a Poisson distribution of the observed deaths.

\section{RESULTS}

During an average of 6.43 person-years of follow-up for 775537 participants, 2626 men (age-standardised mortality rate (ASR) 65.1 per 100000 ) and 170 women (ASR 17.1 per 100000$)$ died from suicide. Table 1 shows the results of SMRs and 95\% CI using the economically active population as a reference population. Overall, occupationally injured workers showed significantly higher mortality compared with the reference population. In subgroup analysis, most of subgroups by employment type, disability and injured site showed statistically significant higher mortality except individuals with severe disabilities, women with moderate disability and head injury.

\section{DISCUSSION}

We found that occupationally injured workers have a higher risk of suicide both in men and women. Contrary to our hypothesis, injured workers with disabilities had lower rates of suicide compared with non-disabled workers.

Our finding of the overall excess suicide mortality of injured workers is in line with previous US studies. ${ }^{78}$ Several possible mechanisms underlying the elevated risk of suicide could be suggested. First, injuries cause loss in income, or in the worstcase scenario, job loss. Previous research found that the income of injured workers dropped by an average of 14\% during the 5 years after an occupational accident in Korea. ${ }^{9}$ In addition, a study on return to work of occupationally injured workers revealed that only half of them returned to work within 12 months, and around $20 \%$ still had no job at the time of 3 years after the accident. ${ }^{3}$ Furthermore, socioeconomically disadvantaged groups at the time of accident experienced more loss of income; for example, daily workers' income dropped by $27 \%$ while permanent workers' income decreased by $7 \%$ during the 5 years after the accident. ${ }^{9}$ This discrepancy might be a factor explaining the higher suicide risk among temporary workers than permanent workers.

An unexpected finding of the current study was the lower suicide risk among more severely disabled compared with nondisabled individuals among men. This appeared to be at odds with prior studies which suggested an increased risk of suicide ideation/suicide among disabled workers. ${ }^{5}$ One explanation for this discrepancy also might be related to the socioeconomic circumstances of injured workers. Surprisingly, the income loss of injured workers without a disability was significantly greater than injured workers with a disability according to previous Korean studies. ${ }^{910}$ The reason of this paradoxical phenomenon might be that severe disability groups (disability rating 1-3) are compensated through a 'disability pension' (70\%-90\% of preaccident salary), while many of non-disabled injured workers could not return to work or earn the same level of income as before the injury. This pattern suggests the need for stronger policies to support non-disabled injured workers to return to work and maintain their income.

A second explanation for the association between occupational injury and suicide could be depression as a mediator. Previous studies reported that the risk of depression was increased among occupationally injured workers compared with non-injured workers or non-occupational injured individuals. ${ }^{4}$ On the other hand, we did not find evidence that head injury (which is the strongest risk factor for postinjury depression) was more strongly associated with suicide risk compared with injuries at other sites.

Finally, disruptions in family life also could play a role in the association. In a previous Korean study, around half of occupationally injured workers felt that closeness in their family decreased and $87 \%$ of them reported feeling pressure to meet their family obligations. ${ }^{11}$

In our data, women accounted only $20 \%$ of study sample, while around $40 \%$ of the workers covered by IACI are women in Korea. This finding is probably due to the majority of injured workers in high risk industries (such as construction and manufacturing) are men. Furthermore, higher background suicide rate in men contributed to the wide gap between the numbers of suicide cases in men versus women.

The current study has significant strengths and limitations. The most obvious strength is that the study sample were drawn from a nation-wide large data of compensated workers rather than selected subgroups. The most important potential limitation of this study is that unmeasured confounders such as preinjury depression or socioeconomic status may influence our results. Residual confounding may have led to an inflation of the risk of suicide following an occupational injury. The coverage of IACI is around $70 \%$ of the total economically active population excluding self-employed, unpaid family workers and workers of small companies in agriculture, hunting, fishery and forestry. 
As socially deprived workers such as contract workers are more likely to be excluded from official compensation, ${ }^{12}$ the suicide rates of occupationally injured workers might be even higher than our estimates. Also, there is a possibility that workers with less severe injury might have been excluded from the study as a result of not claiming compensation. We could not exclude occupationally injured workers from the economically active population (used as the reference in the calculation of SMRs). Therefore, some part of the study population is also included in the reference population, though the share of them is likely to be very small. This potential double-count likely diluted the impact of occupational injury on suicide.

In conclusion, our study shows that occupationally injured workers have a higher risk of suicide. Social policies to protect and support injured workers are needed, as well as stronger policies to prevent workplace injuries.

Contributors All authors discussed the results and commented on the manuscript. Specifically, IKim conceptualised and designed the study, and collected the data. $\mathrm{H}$-EL analysed the data and wrote the manuscript. M-HK and IKawachi revised it critically as regards important intellectual content.

Funding This study was funded by Hanyang University (HY-2015).

Competing interests None declared.

Patient consent for publication Not required.

Ethics approval This study was approved by the Institutional Review Board of the Hanyang University (IRB No. HYI-16-029-6).

Provenance and peer review Not commissioned; externally peer reviewed.

Data availability statement Data are available upon reasonable request. The data sets used and analysed during the study are available from the corresponding author on reasonable request.

Open access This is an open access article distributed in accordance with the Creative Commons Attribution Non Commercial (CC BY-NC 4.0) license, which permits others to distribute, remix, adapt, build upon this work non-commercially, and license their derivative works on different terms, provided the original work is properly cited, appropriate credit is given, any changes made indicated, and the use is non-commercial. See: http://creativecommons.org/licenses/by-nc/4.0/.

\section{ORCID iDs}

Hye-Eun Lee http://orcid.org/0000-0003-4648-5042

Inah Kim http://orcid.org/0000-0001-9221-5831

\section{REFERENCES}

1 OECD. Suicide rates [Internet], 2020. Available: https://www.oecd-ilibrary.org/socialissues-migration-health/suicide-rates/indicator/english_a82f3459-en [Accessed 24 Mar 2020].

2 Kim M-H, Jung-Choi K, Jun $\mathrm{H}-$ J, et al. Socioeconomic inequalities in suicidal ideation, parasuicides, and completed suicides in South Korea. Soc Sci Med 2010;70:1254-61.

3 Park EJ. The study of the first return-to-work of injured workers. Korean Journal of Social Welfare 2012;64:359-81.

$4 \mathrm{Kim}$ J. Depression as a psychosocial consequence of occupational injury in the US working population: findings from the medical expenditure panel survey. BMC Public Health 2013;13:303.

5 Lee S-U, Roh S, Kim Y-E, et al. Impact of disability status on suicide risks in South Korea: analysis of national health insurance cohort data from 2003 to 2013. Disabil Health J 2017:10:123-30.

6 Ahn Y-S, Bena JF, Bailer AJ. Comparison of unintentional fatal occupational injuries in the Republic of Korea and the United States. Inj Prev 2004;10:199-205.

7 Martin CJ, Jin C, Bertke SJ, et al. Increased overall and cause-specific mortality associated with disability among workers' compensation claimants with low back injuries. Am J Ind Med 2020;63:209-17.

8 Applebaum KM, Asfaw A, O'Leary PK, et al. Suicide and drug-related mortality following occupational injury. Am J Ind Med 2019;62:733-41.

9 Bae SW, Oh SS, Park WM, et al. Changes in income after an industrial accident according to industry and return-to-work status. Int J Environ Res Public Health 2019;16. doi:10.3390/ijerph16142603.

10 Bae S, Yun S, Lee Y, et al. Income changes due to disability ratings and participation in economic activities caused by industrial accidents: a population-based study of data from the fourth panel study of workers' compensation insurance (PSWCI). Int $J$ Environ Res Public Health 2018;15:2478.

11 Moon W. A study on family environment changes after worker's injury in an industrial accident. Graduate School of Public Health Yonsei University, 2009.

12 Park JS. Risk-shifting and institutional lag: industrial accident statistics of regular workers and inside contract workers at the Hyundai motor Ulsan plant. Korean I Labor Stud 2007;13:213-48. 